\title{
The Shape of Services to Come: Values-Based Reference Service for the Largely Digital Library
}

\author{
Chris D. Ferguson and Charles A. Bunge
}

\begin{abstract}
Much has been said about the technological dimensions of the largely digital library of the future, but little has been said about the service values librarians must advance to make this environment work effectively for all of the library's users. Libraries must retain the timeless service values of equity of access, personal service, and services tailored to the needs of individuals while exploring new values such as integrating technologies, maintaining holistic computing environments, delivering core services through the network, making technology work for all, and collaborating across administrative lines.
\end{abstract}

Is a library simply an organized collection of books and reference materials, or is it one of the last free physical spaces devoted to public discourse and discovery? Whatever the answer, no software application will replace a good human reference librarian any time soon. ${ }^{1}-$ David Pescovitz

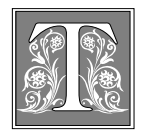

hough unmeasured and largely undescribed, it is becoming increasingly clear that a transforming convergence of computer user rooms and library public spaces is well under way within academic libraries. It is equally clear that the institutions most likely to advance fastest along the continuum from the largely paper to the largely digital library are those with productive working relation- ships among library professionals and technologists who recognize the mutual benefits of collaboration. The computer network has had a revolutionary impact on the entire Weltanschauung of academic librarianship, from the ways librarians view their services to the ways they view clients, even to the ways they view themselves. The network compels librarians to seek new alliances, to radically change their perspectives on user needs, and even to transform the ways in which they organize themselves to serve these needs.

Yet even as academic librarians embrace computer user rooms and networks within the library, they recognize the need to work aggressively to bring the library into user rooms, residence halls, offices, and anywhere else the network goes. This does not speak to just access to information provided by the li-

Chris D. Ferguson is Assistant Dean for Redesign of Subject Libraries at the University of Southern California; e-mail: cferguso@calvin.usc.edu. Charles A. Bunge is a Professor in the School of Library and Information Studies at the University of Wisconsin-Madison; e-mail: bunge@macc.wisc.edu. Portions of this article were presented to the LITA/LAMA National Conference in Pittsburgh, October 1996. 
brary or support for use of the network from locations inside the library but, rather, to the full range of services and support to an extent and of a nature heretofore barely imagined deliverable outside the confines of the library itself. No longer is it sufficient to provide online catalogs, electronic periodical indexes, and full-text databases in a networked environment. Every day, the need becomes more apparent to deliver highquality reference and instructional support through the network to all users of the library at all times and from all locations, commensurate with the expansion of the information and resources available for unmediated access from remote locations.

Little attention has been given to the nature and quality of library service that will be required in a largely digital age. This article begins to frame questions related to library service values in such an environment-the beginning of what surely will become a very important, very lengthy, and possibly very intense dialog among librarians, technologists, and interested parties from other teaching and learning communities regarding the roles of, and services provided by, what now are known as public services or reference librarians. It is important to enter into these discussions with a command of how, as a profession, librarianship has responded to change in the past; an understanding of the ways in which librarians presently are exploring new approaches; and convictions regarding values that have defined, and will continue to define, the librarian's role as service provider.

\section{The Future Is Now}

Buckland describes the three phases of modern and future libraries as the paper library, wherein materials collected and technical operations are based largely on paper; the automated library, which sees the computerization of most operations while collections remain largely paper; and the electronic library, wherein both operations and collections for the most part originate, are stored, and are used in electronic formats. ${ }^{2}$ Lynch distinguishes between an era of modernization, in which technology is employed "to continue to do what [librarians] have been doing, but in a more efficient and/ or cost-efficient way"; and an era of trans-

\section{It becomes more a concept with emphasis on services than a place with emphasis on collections.}

formation, where librarians use "new technology to change processes in a fundamental way." ${ }^{3}$ Both Buckland and Lynch likely would agree that just as information technology in the classroom and as a scholarly communication tool has moved into takeoff, so too (and certainly not coincidentally) have academic libraries moved into a critical - a takeoff-phase between automation and digitization, between modernization and transformation.

Just how academic libraries will be defined in five or ten or twenty years is less important than the incontrovertible fact that they will be highly digital and probably largely digital. Along with a shift from the largely paper to the largely digital library comes a shift away from the model of library as locus for information. The proliferation of digital resources, services, and tools increasingly aids the delivery of information to the desktop with an increasing proportion of these connections occurring directly between information consumer and information producer. As libraries digitize collections and provide more and more direct access, they also must seek ways to provide their full range of services over the network, either digitally or through real-time interactions. As the library truly becomes more user-centered and provides information and information access to the desktop, it becomes more a con- 
cept with emphasis on services than a place with emphasis on collections. It should be little surprise, then, that the role of the academic librarian is now rapidly shifting, as has been anticipated for some time, from information provider to information access consultant.

The term digital library unnerves many librarians because it seems to preclude so much they know and value, but they need not assume that this means an elimination of the constituent features or values of contemporary academic library services. Most technologists writing on this subject understand that the future is uncertain and recognize that discussions of digital libraries explore just one component in the comprehensive information services that will evolve over the next decade or two. ${ }^{4}$ Librarians must view these discussants as partners, not opponents, and must insinuate themselves even into theoretical discussions of the digital library, contributing to the dialog a recognition of the need to make such resources available to all through the parallel development and delivery of value-added and values-based services created and maintained by librarians. In particular, librarians must recast the longlived service values of equity of access, personal service, and services tailored to individual needs into such newly emerging values as technology integration, holistic computing, delivery of core services through the network, special efforts to make the technology work for all, and collaboration across administrative lines.

\section{Evolving Models for Reference \\ Services}

Reference service has been one of the focal points for library responses to the changes outlined above. Growing out of a sense of crisis in the 1980s, a variety of new approaches to providing reference service has evolved. Ferguson and Cox have provided overviews of this evolution. ${ }^{5}$ They cite a number of reports on new or different models for providing reference service and note that the search for ways to apply the models in local situations is a frequent subject on listservs such as LIBREF-L. The major elements in these models, and the major dimensions along which change has occurred, are: (1) the location for providing assistance, (2) staffing configurations, and (3) the services and activities involved.

\section{Reference Service As Place?}

Central to the "traditional" model for reference service is the reference desk. This is a highly visible service point, staffed by professional librarians, that invites queries ranging from simple requests for directions to complex questions requiring extended assistance. This model symbolizes values such as ease of access, equity, and high-quality service. However, as the increase in volume and complexity of client needs collided with budget and staffing constraints, librarians began to see that the reference desk could "actually act more as an impediment than a facilitator to high-quality assistance. . . ."6 Ferguson and Whitson summarize the arguments that have been raised for seeking alternatives to the reference desk as the focal point for reference service. ${ }^{7}$

One such alternative with a long history is that of dividing the reference desk into two or more service points for progressively more complex or in-depth service. Now commonly called tiered service, this model usually involves the establishment of an "information desk," at which directional (and perhaps simple reference and catalog use) questions are answered. The reference desk (or desks) is thereby enabled to deal with questions that require more lengthy and complex interactions between librarians and users. A 1991 survey by the ARL provides information on this phenomenon in academic libraries, as do Ferguson and Cox in their literature reviews. ${ }^{8}$

Another alternative is to get the reference staff out from behind the desk. One of the disadvantages of the high-volume 
reference desk is the tendency of its staff to get trapped at the desk by the flow of clients, the need to answer the telephone, and other constraints. Librarians have recognized that such entrapment inhibits good service, especially as more and more electronic workstations are located away from the desk. One response has been the creation of "roving" librarians, who are specifically assigned to spend at least part of their "desk-duty" time circulating among users and workstations offering assistance as needed. Rettig discusses this trend briefly, and the topic has been discussed on the LIBREF-L listserv over the past several years. ${ }^{9}$

What has been called the "research consultation" model takes the evolution away from the "reference service as place" model one step further, by entirely replacing the reference desk with a combination of an information desk and an office-based consultation service. Widely discussed in the "rethinking reference" literature, this model is most closely identified with reorganizations at Brandeis and Johns Hopkins led by Virginia Massey-Burzio. ${ }^{10}$ In this model, requests for assistance that are not directional in nature or that cannot be satisfied from ready-reference sources within a few minutes are answered in an office environment that is conducive to librarian/ client interaction, rather than at a hectic reference desk.

Other alternatives to the "reference service as place" model recognize the fact that many clients who need assistance are not in the library and do not wish or need to come to the library to interact with information sources. Cox calls one such alternative "Going Out to the User," wherein reference librarians work directly with users in the users' own environments. ${ }^{11}$ Mardikian and Kesselman mention such strategies as librarians establishing office hours in campus departmental offices, holding joint office hours with teaching faculty, and working in partnership with teaching faculty to pro- mote and achieve information literacy. ${ }^{12}$ Other ways to allow users to gain assistance in finding and using information, wherever they may be, include reference service via e-mail, computerized self-service instructional programs, computerized information kiosks, reference expert systems, and the design and implementation of interfaces and help systems to assist users in navigating the world of information and in linking with appropriate resources. ${ }^{13}$

\section{Reference Staff As Generalist Profession- als?}

In the "traditional" reference service model, the reference desk is staffed with professional reference librarians. This model assumes that only professionally trained staff can (1) recognize the varying levels of need that clients bring to the desk, (2) conduct the reference interview that is so often necessary to understand the real need behind the query as stated, and (3) answer the complex questions that can come to the desk anytime it is open. This staffing model symbolizes the value that reference librarians place on high-quality, individually tailored service to those who need assistance. As Whitson points out, this model "maximizes the likelihood that the real information need

\section{Another alternative is to get the reference staff out from behind the desk.}

will be uncovered and addressed."14 Many argue, however, that this model also entails inflexible and inefficient use of staff, requiring highly skilled librarians to answer directional and simple reference questions while important complex and high-level tasks cannot be accomplished due to lack of staff time. He summarizes the literature and arguments for developing other staffing configurations for reference service. ${ }^{15}$ 
The most commonly mentioned alternative model is the employment of paraprofessionals at the reference desk. Typically, paraprofessional staff are expected to handle directional questions and simple ready-reference questions, while referring more complex questions to professional staff. The information desk, mentioned above, is usually staffed by paraprofessionals, but general reference desks also can have some combination of professional and paraprofessional staff. Ferguson's review discusses some of the trends and issues related to this model. ${ }^{16}$

The advent of electronic workstations in the reference area, especially CD-ROM workstations with printers, brought renewed attention to user needs for technical or mechanical assistance. Reference librarians found themselves helping users boot computers, install discs properly, and make balky printers work, none of which seemed to be appropriate duties for professionals. In an early article on this problem, Bonta and Kalin discuss the establishment of a new staff position entitled reference technology assistant, a specialized paraprofessional position. ${ }^{17}$ In his article on a "differentiated services" reference model, Whitson discusses the need for technical assistance, noting that "many libraries now assign student employees or support staff to assist users with CD-ROMs or assist in an electronic resources area." 18

The expansion in the number and complexity of information resources, and in the means for accessing and manipulating them, has increasingly called into question the "every reference librarian a generalist" model. One of the rationales for the staffing model used at Rutgers is that "it is impossible for any one librarian to be an expert on all resources and systems," and Whitson argues that it is no longer feasible to "maintain the kind of general competency reference librarians used to take for granted." 19 Specialization can occur along a variety of di- mensions. For example, from the time when reference staffs commonly had one or more members who were recognized as online searching experts to the current recognition of the special talents of Internet "gurus," reference staffs have worked out a variety of ways to develop configurations of specialized knowledge and skills needed to use technology effectively. Some reference staffs have recognized that such configurations should include close collaboration with staff of the campus computing or information technology service. Perhaps staffing reference or information access services with a combination of personnel from the library and the computing service is the logical extension of this trend. Shapiro and Long discuss a process that resulted in the creation of "a User Services Department consisting of the core user services operations from both the library and computing." 20

Subject specialization certainly has long been a feature of reference staffing patterns, and some argue that it is all the more important now. Other specialties reflected in current staff differentiation arrangements include bibliographic instruction, expertise in certain complex information systems or means of access, user needs assessment, interface design, and expert systems.

Mentioning interface design and expert systems raises another reference staffing issue, i.e., whether certain "traditional" reference services should require staffing at all. As librarians study and analyze the user needs that are reflected in the questions asked at service points, they are increasingly aware that these needs are recurring and repetitive, and that the knowledge and skill required to respond to them, previously available only from librarians, can be encoded into expert systems and improved interfaces with information sources. Brandt, Campbell, and Bryant argue that "many of the traditional reference inquiries will be handled by improved interfaces and 
help systems that librarians will play a primary role in developing." 21 The Rutgers Hierarchical Reference Staffing Model includes a level called "Minimum Human Intervention" that includes such alternatives to staff members as computerized information kiosks, computer-assisted self-service instruction, self-guided building tours, and improved signage and maps. ${ }^{22}$

\section{Reference Service As Answering Questions?}

The defining characteristic of "traditional" reference service is answering questions posed by users. Other activities carried on in the reference department or service are supportive of (or distractions from, depending on one's point of view) this central function. This model symbolizes the value that reference librarians place on personal service and on tailoring service to the needs of individual users at the time they are experiencing difficulties in finding and using information. However, many librarians argue that this model for reference service does not reflect adequately the great diversity of users (and potential users), their information needs, and their informationseeking behavior nor does it reflect changes in information sources and in the management and organization of libraries. In newer models, answering reference questions is only one of a wide variety of functions and activities that make up reference services.

One of the oldest "additional" functions or activities is bibliographic instruction. Ferguson discusses the arguments that have been made for and against the inclusion of instruction in the reference "paradigm." ${ }^{23}$ Some authors who discuss new models for reference service argue that there should be increased emphasis on instruction, including specialized instruction for particular client groups, the development of computer-assisted instruction, and the integration of information literacy into the curriculum. Brandt and others predict that reference will "metamorphose into education and system design" at their library. ${ }^{24}$

Mediated online searching is another set of activities that has been added to question-answering in newer models of reference service. Although the number of mediated online searches has decreased dramatically in most academic libraries, other duties associated with helping users access and use information in electronic formats have developed. These include providing technical assistance with hardware and software problems, preparation of guides to the selection and use of library resources, and the design of interfaces and help systems for electronic information resources.

Changes in the management and organization of libraries and emphasis on customer service have brought to reference staff increased responsibilities for planning, evaluation, and participation in management teams and task forces. Ferguson discusses the impact that changes in management have had on models for reference services, and Rettig comments on the expanded efforts of libraries to understand the information needs of users and potential users. ${ }^{25}$

Increased knowledge of library users and their needs, and an ever-widening variety of service alternatives to serve them, have impelled reference librarians to analyze their operations in order to get a more systematic view of services and activities so that effective staffing patterns can be developed. As an alternative to the "one service" or "reference as answering questions" model, Whitson posits five differentiated services (directions and general information, technical assistance, information lookup, research consultation, and library instruction), each of which has a progression of increasingly more complex elements. ${ }^{26}$ Mardikian and Kesselman divide user needs into broad categories such as information, instruction, and access assistance. Within each category, they list a variety of services, organized by complexity and the need for varying levels 
of staff expertise and specialization. ${ }^{27}$ Reference services in the electronic environment, then, encompass a mix of function and activities that include personal assistance as but one component.

\section{New Models, Traditional Values}

Just as few, if any, libraries have implemented the "traditional" model of reference service in its pure form, there is no one "new" model, or even a small number of them, that can be seen in pure form in libraries today. Most knowledgeable observers, however, would agree with Janice Simmons-Welburn when she says, "I see our new reality for reference as an organizational network of services. . . . A network of reference and information services can accommodate consultation, on-demand assistance, and instruction as

The value placed on high-quality service is reflected in increased attention to evaluation and the effective use of a variety of staff specialties and levels of expertise.

different, yet highly compatible nodes that are themselves distinctive yet responsive to one another." ${ }^{28}$ In this network of services, the value placed on convenient and equitable service to users is acted upon by taking services out to the users, wherever they are at the time of their need. The value librarians give to individually tailored service is acted upon through continuing study of users' needs and the development of multidimensional services to address those needs. The value placed on high-quality service is reflected in increased attention to evaluation and the effective use of a variety of staff specialties and levels of expertise. And the value placed on personal service, that hallmark of reference, is honored by offering users the opportunity to consult with reference librarians in environments that are conducive to fruitful interaction.

\section{Service Values for the Largely Digital Library}

As libraries continue in an era of constant change under pressure to deliver valueadded services while continuously improving the quality of these services, they would do well periodically to rethink their core values and to bring into awareness new values that match users' evolving needs and expectations. ${ }^{29}$ Direct-user access to information in digital format (less elegantly known as de-intermediation) and essential services through computer network environments are two powerful emerging phenomena for which librarians necessarily must evolve a set of values that will shape services in academic libraries for the next several years. Continued integration of paper and electronic technologies, creation and support of holistic computing environments, delivery of reference and instructional services over the network, special efforts to make the technology work for all users, and partnering across administrative lines build on the traditional reference values of personal service and equity of access in support of more contemporary notions of direct-user access to information and services in a networked environment.

\section{Integration of Technologies}

While enroute from automated to truly electronic libraries, this is a transitional period with much ambiguity and uncertainty. Librarians are technologically capable of creating the largely digital research library in the very near future, but a complex of fiscal, psychological, and even sociological barriers prevent them from doing so anytime soon. ${ }^{30}$ To date, and despite some rugged going in the later 1980s, academic libraries on the whole have done a remarkable job of incorporating online searching, online catalogs, CD-ROMs, and some full-text resources into their service delivery routines. And as the ability to purchase and store information locally has de- 
creased in relation to perceived needs, librarians have learned to make painful choices among print-based resources and between print and digital resources.

Certainly, libraries must continue these efforts as necessary dimensions of the transition from a largely paper to a largely digital environment. But just as surely they need to explore more adaptive service delivery configurations that will meet their needs in the present and yet possess inherent flexibility for the inevitable shift away from paper. For example, an alternative to a branch library system as most academic libraries know it might be the large-scale proliferation of some combination of an electronic integrated library system that emphasizes direct-user access to both fulltext and bibliographic resources, a highquality document delivery service, reference and instruction services delivered around the clock over the network, and a research consultant located in an office within appropriate departments and schools. Various of these elements have been developed or prototyped in recent years, but not yet have they come together in a way that enables continued use of paper as needed while affording flexible and proportionate adaptation to increasing use of digital resources, all the while providing personal, value-added services in situ.

\section{Holistic Computing}

As has been observed by many librarians in a variety of contexts, users are looking at libraries in different ways. The availability of Web browsers and e-mail readers from within libraries and the availability of online catalogs, periodical indexes, and full-text resources over the network from user rooms, offices, and homes are breaking down conventional notions of what a library is or ought to be. Computer user rooms and libraries are converging, especially from the perspective of remote workstations, but increasingly from workstations within the library itself. The next logical step along this path is holistic computing from within libraries, a user environment currently found in most computer user rooms and on most remote workstations.

Holistic computing environments include connectivity and solid representation from all the major tool groups necessary for a balanced research diet: electronic bibliographic tools (online catalogs, periodical indexes, full-text resources) for the preliminary phases of research; network navigation and communication tools (Web browsers, gophers, Telnet, e-mail readers, FTP) for the acquisition of additional information in various formats through networks and from colleagues worldwide; and productivity tools (word processing, spreadsheets, graphics software, and even basic multimedia development packages) for the assembly, manipulation, and delivery of the final research product from a single workstation.

Many library users are satisfied with the availability of bibliographic and network navigation tools over the network and are content to contribute their own productivity tools to the mix on their personal machines. But many other users, especially students, are increasingly less tolerant and understanding of why bibliographic tools are available in computer user rooms along with productivity tools, yet this is not the case in libraries. At present, if one starts in the library in order to receive expert support in locating and working with research materials, one usually has to go elsewhere to complete the steps of transforming information into knowledge. But if the person begins in a computer user room, he or she is much closer to one-stop shopping, albeit with the potential for loss due to the lack of on-site reference or instructional assistance. In a broader sense, as electronic resources proliferate and connectivity expands, library users are increasingly coming to expect all the tools and resources they need available from 
their workstation of choice. Computer user rooms and libraries are converging, and it is certain they will continue to do so for the foreseeable future. And considering that campuses likely will increase their reliance on licensed software delivered from fileservers, while libraries increase their use of client/server arrangements for the provision of digital resources over networks, this trend most likely will accelerate.

The key here is to focus on the full set of skills and knowledge needed to make students competitive in the workplace and able to engage in lifelong learning, which includes information retrieval and manipulation in a seamless environment, while making the core services available through the network so that library, even to librarians, is defined less by locus and more by electronic equivalents of what has transpired in libraries for decades.

\section{Core Services through the Network}

To the same extent that direct access over the network continues to supplant paper repository as the prevailing library metaphor, and to the degree the users of libraries become more accustomed to accessing library-sponsored materials and services in ways and at times that match their preferences and lifestyles, we will

\section{At present, reference service is technologically relatively easy to provide to remote locations.}

be advancing to the largely digital and user-centered library. ${ }^{31}$ Parallel to this evolution must be the metamorphosis of the library's core user services, particularly reference and instruction, in ways that enable delivery over the network in order to achieve a high degree of user independence, anywhere the network goes and at any time the user chooses.

At present, reference service is technologically relatively easy to provide to remote locations. Indeed, libraries have been doing so for decades with the assistance of telephones and, more recently, electronic mail. It is time, though, to build on this foundation with a variety of technologies that would enable libraries to bring real-time reference service into the network in a routine and broad-based fashion. Network-based videoconferencing (especially with whiteboard functionality that enables the convenient transfer of images and data) and the combination of cordless phone and screen-grabbing technology in computer user rooms are just two ways in which libraries can begin extending reference support to users accessing their systems via the network. Just as important would be the experience of making necessary staffing realignments and conceptual adjustments that would enable libraries more readily to absorb and adapt still other technologies for this purpose as they appear. Combine such an initiative with current thinking on tiered information/reference service in libraries, customer service practices in the business world, and the likelihood of other campus agencies wanting to participate in something akin to an information and referral service, and one realizes that it is not a great stretch of the imagination to envision a seven-day/twentyfour-hour user support service under the auspices of the library from a single-service point to many libraries, computer rooms, and individual networked users.

Equally intriguing are the prospects for providing interactive instructional opportunities over the network, especially with the advent of relatively painless multimedia through World Wide Web technology. In this case, the challenge is not so much to be available when the need arises, but to be sufficiently sophisticated and robust to address the need when the user chooses. Many libraries are moving forcefully in this direction but still have far to go before achieving information systems that are truly integrated with fully interactive and user- 
directed instructional components.

Instruction librarians have known for some time that course-related instruction-instruction at time of need with a specific learning focus, what Dusenbury and Pease term the teachable moment-is far superior to general, in-case-of-need instruction..$^{32}$ What could be more effective utilization of the teachable moment than providing the means for users to invoke instructional support modules precisely when and where they are needed? Surely this virtue extends to reference service as well, with an even greater potential for collaboration among institutions, especially during low-traffic times. Not only might two or three neighboring institutions draw on networking and telecommunications technology to share the burden of information/reference support during low-demand periods, but it is theoretically possible for institutions in Tokyo, Los Angeles, and London to provide twenty-fourhour coverage with each participant operating only during his or her respective daytime work hours.

\section{Make the Technology Work for Everyone}

It has often been said that the 1970s was the decade of the minicomputer, the 1980s was the decade of the desktop personal computer, and the 1990 s is the decade of the network. To this should be added that the latter part of the 1990s and the beginning of the twenty-first century is the era in which the network is made to work on a human scale and in a humane fashion. Much of the ground covered thus far-integration of technologies, holistic computing, core services through the network - is part of a desire to make the technology work for everyone, not just the technologically adroit. What for most librarians is an instinctive impulse to make technology easier for their users is in fact a service value rooted in their long-standing traditions of personalized service and equity of access-what might be called these days ubiqui- tous access to value-added service.

Yet there remain additional notions to be addressed in order to advance this impulse to make things work for all library users. For starters, all libraries should engage in dynamic and multifaceted instructional programs that include a rich selection of drop-in workshops from which users can select content and level of expertise suited to their needs, courserelated efforts that address learning needs within the curriculum, and large portions of, or entire courses on, information lit-

\section{The network has become both tool and metaphor.}

eracy and technology awareness. If academic and faculty status for librarians is not a charade perpetrated for their own self-esteem, then they should be prepared to exert the greatest effort possible to accomplish both independent and collaborative opportunities for bringing information literacy and technology awareness into the curriculum on a large scale and in meaningful ways.

The article also has spoken of network-based information/reference service, but maintenance of this service in person in the library should not be forgotten. And in a library that offers holistic computing as well, this entails providing software consulting support, tiered service with a strong referral component, and a higher degree of proactive engagement than is ordinarily found even in the more progressive academic libraries.

\section{Collaboration across Administrative Lines}

The network has become both tool and metaphor. An explosion of networked computer communication, globalization of information and commerce, and reengineering and restructuring as a way of life have in part fostered and in part derived additional momentum from increased interpersonal networking, col- 
laboration, teamwork, partnering, and other popular dimensions of cooperative approaches to problem definition and resolution. ${ }^{33}$ Higher education has been no less affected by these trends than the commercial sector, especially as libraries and computing centers emerge from an era of competition and enter one of cooperation. Librarians and computer technologists now typically work together, often feverishly, to build campus infrastructures for information technology, including communications networks, applications architectures, hardware architectures, internal management systems, and access to a large array of appropriate data sources. ${ }^{34}$ Toward this end, librarians more often are turning up as chief information officers, computer centers and libraries are undertaking joint appointments, and on some campuses these organizations are merging in whole or in part.

The simple fact is that computing operations and libraries are learning they need each other to enhance the value of their respective services. Or still more simply put, no longer can any single administrative unit hope to deploy and remain current with networking and information technology, instructional technology for the classroom, a curricular framework for the delivery of content, and a service infrastructure for understanding and matching the needs of many user communities with the expanding universe of potential information resources. Some have taken top-down and others bottom-up approaches to collaboration, but in any case virtually all U.S. colleges and universities are starkly aware of the need to work beyond, around, and through traditional administrative structures to assemble the partners needed for excellence in the information age. ${ }^{35}$

In practical terms, and from the library perspective, collaboration therefore means expanding opportunities for working across reporting lines and flattening the organization within the library, establishing and working jointly with technolo- gists outside the library to achieve defined goals, finding ways to routinize cooperative thinking and acting (e.g., forming bridge organizations consisting of both library and computing operations personnel), working collaboratively with faculty and administrators to advance the educational goals of the institution, and developing still richer combinations of these unions that may uniquely be possible at given institutions.

\section{Shaping Services to Come}

The evolution of new models for reference services and their applications in the largely digital library sketched out above are best viewed as parts of a continuing process of change-change that seems to be occurring with dizzying speed and bewildering complexity. What constants or enduring basics might be used as touchstones or guides to shape this process effectively?

Those who need information and ideas to accomplish their goals-students, faculty, and other staff-make up one of those enduring basics. Analyses of user needs and library use patterns have played an important part in the evolution of the new service models discussed earlier in this article. Respect for users, in all their diversity and complexity, will continue to be at the center of the library's value system. The constant pursuit of knowledge of users' needs and their information-seeking and use behavior will increase the effectiveness with which information services are designed. This will be true, however, only if the service design is based on real needs and actual user behavior patterns, rather than on wishful thinking and untested assumptions. A realistic recognition of users' needs for access to bibliographic tools and productivity tools at the same workstation, for example, underlies the increasing value being placed on holistic computing in academic libraries.

Another enduring basic is the scholarly communication system that seeks to 
provide the information and ideas that the library's clients and potential clients need. Dramatic change in this system has been one of the driving forces behind the changes in library services discussed above. Ensuring effective access to and use of information sources in this system is a key element in the value system of reference librarians. Effective service will depend on their continuing attempts to understand and gain skill in using information sources and surrounding technologies. The fact that scholarly communication is increasingly networked communication heightens the importance of the service value of collaboration across administrative lines in the largely digital environment.

A third enduring basic is the continuing need of information users for assistance in gaining access to information sources. The library and librarianship have evolved to provide services that bring together users and the information they need. Within libraries, reference service provides the personal touch, and it has developed to help individual users and potential users overcome the barriers they confront in their pursuit of information and ideas. This service adds value to information resources by helping individual users find them and put them to use in their lives. This valueadded service is also a values-based service in that it rests on or reflects certain values in library services. These values can serve as touchstones to guide the change process. What are some of these values, and how will they be reflected in the largely digital library?

A primary value for reference service is equity and equal access to information. Reference service has developed to ensure that not only adroit users or the welloff are able to find and use information. In the largely digital environment, this value will take the form of making technology work for everyone. As libraries plan and implement services for the future, they will need to make sure that the use of information technology is put within the grasp of all their users, whether through the design of systems that are easy to use, the development of effective instructional programs, or the provision of personal assistance when and where needed.

Reference service also places value on freedom of choice for the library's clients. Librarians help them realize their own goals, rather than forcing them to use information sources on the library's terms. Librarians value freeing and facilitating, rather than controlling and manipulating. These "traditional" values are one of the bases for the increasing value that reference librarians are placing on providing core services through networking. This means that they will use technology to develop information systems that provide alternatives and choices for the library's users, allowing them independence when they want it and providing personal assistance when it is needed and desired.

Intellectual and academic freedom is a core value for librarianship and for reference service, as are privacy and confidentiality in information-seeking and use. Many issues related to these values will arise in the largely digital environment. As libraries design and implement information services for the future, it will be important that they not let fear of the power of technology, tendencies toward in loco parentis, or other concerns cause them to lose sight of the importance of these values.

The paths that various academic libraries take toward largely digital information services will vary widely, and even the various manifestations of the largely digital library that eventually develop will be only points along yet longer paths. The host of factors - from local to global and from human to technological-that must be considered in planning and implementing library services can be challenging, if not overwhelming. Although it will not make the process sim- 
pler, using certain enduring basics and core values as touchstones and guides can increase the probability of success. These include understanding of information needs and users, knowledge of communication and information systems, and commitment to the values that have developed over the decades in reference services. Increasingly, this will include a commitment to integration of technologies, holistic computing, bringing core services into the network, making technology work for all, and collaboration across administrative lines.

Sometimes reference librarians get so close to, or so enmeshed in, the problems and frustrations of rapid change that they begin to wonder whether they will have a role in the evolving information environment. Both within librarianship and the public at large, however, there is renewed recognition that it is simply in the nature of a dynamic communication sys- tem that the development of information sources will run ahead of organization and access tools and mechanisms, and that there will be a continuing need for the services that reference librarians provide. There have been a number of items in the popular press that argue the importance of librarians in the new milieu. ${ }^{36}$ They point out that the skills librarians have in helping people articulate and focus their information needs, as well as skills in identifying, evaluating, and manipulating information sources to serve a particular information need, will continue to be needed in the foreseeable future. And, as one article says, "The most critical and underestimated advantage librarians bring to bear is the most obvious - the human touch." ${ }^{37}$ The challenge for reference service in the largely digital library will be how to extend this human touch to highly diverse and widely dispersed clients whenever and wherever they want and need it.

\section{Notes}

1. David Pescovitz, "Reality Check: The Future of Libraries," Wired 3, no. 12 (Dec. 1995): 68.

2. Michael Buckland, Redesigning Library Services (Chicago: ALA, 1992), 5-6.

3. Clifford A. Lynch, "The Transformation of Scholarly Communication and the Role of the Library in the Age of Networked Information," Serials Librarian 23, nos. 3-4 (1993): 5-20.

4. Gio Wiederhold, "Digital Libraries, Value, and Productivity," Communications of the ACM 38, no. 4 (Apr. 1995): 85-96; David M. Levy and Catherine C. Marshall, "Going Digital: A Look at Assumptions Underlying Digital Libraries," Communications of the ACM 38, no. 4 (Apr. 1995): 77-84.

5. Chris Ferguson, "Reshaping Academic Library Reference Service: A Review of Issues, Trends, and Possibilities," Advances in Librarianship 18 (1994): 73-109; Suellen Cox, "Rethinking Reference Models," available at http://www-lib.usc.edu/Info/Ref/Cox/rethink_ref.html, (May 1996).

6. Virginia Massey-Burzio, "Reference Encounters of a Different Kind," Journal of Academic Librarianship 18, no. 5 (Nov. 1992): 277.

7. Ferguson, "Reshaping Academic Library Reference Service," 88-89; William L. Whitson, “Differentiated Service: A New Reference Model," Journal of Academic Librarianship 21, no. 2 (Mar. 1995): 104-5.

8. Denise Forro, Lori A. Goetsch, and Clifford A. Haka, Information Desks in ARL Libraries SPEC Kit no. 172 (Washington, D.C.: ARL, 1991); Ferguson, "Reshaping Academic Library Reference Service," 89-90; Cox, "Rethinking Reference Models."

9. James Rettig, "Islands in a Sea of Change," in Rethinking Reference in Academic Libraries, ed. Anne G. Lipow (Berkeley, Calif.: Library Solutions Pr., 1993), 79.

10. Massey-Burzio, "Reference Encounters of a Different Kind," 276-80; Douglas Herman, "But Does It Work? Evaluating the Brandeis Reference Model," Reference Services Review 22, no. 4 (winter 1994): 17-28.

11. Cox, "Rethinking Reference Models."

12. Jackie Mardikian and Martin Kesselman, "Beyond the Desk: Enhanced Reference Staffing for the Electronic Library," Reference Services Review 23, no. 1 (spring 1995): 27-28.

13. Ibid., 26-28; Eileen G. Abels, "The E-mail Reference Interview," $R Q 35$, no. 3 (spring 1996): 
345-58; Lara Bushallow-Wilbur, Gemma DeVinney, and Fritz Whitcomb, “Electronic Mail Reference Service: A Study," RQ 35, no. 3 (spring 1996): 359-71.

14. Whitson, "Differentiated Service," 104.

15. Ibid., 103-5.

16. Ferguson, "Reshaping Academic Library Reference Service," 90-92.

17. Bruce Bonta and Sally Kalin, "CD-ROM Implementation: A Reference Staff Takes Charge," Reference Services Review 17, no. 2 (1989): 10-11.

18. Whitson, "Differentiated Service," 105.

19. Mardikian and Kesselman, "Beyond the Desk," 22; Ibid., 103.

20. Beth J. Shapiro and Kevin B. Long, "Just Say Yes: Reengineering Library User Services for the 21st Century," Journal of Academic Librarianship 20, nos. 5-6 (Nov. 1994): 287-88.

21. Kerryn A. Brandt, Jayne M. Campbell, and Willard F. Bryant Jr., "Reflections on Reference Services," Journal of the American Society for Information Science 47, no. 3 (Mar. 1996): 212.

22. Mardikian and Kesselman, "Beyond the Desk," 24.

23. Ferguson, "Reshaping Academic Library Reference Service," 99-101.

24. Brandt, Campbell, and Bryant, "Reflections on Reference Services," 212.

25. Ferguson, "Reshaping Academic Library Reference Service," 94-96; Rettig, "Islands in a Sea of Change," 79-80.

26. Whitson, "Differentiated Service," 103-110.

27. Mardikian and Kesselman, "Beyond the Desk," 21-28.

28. Janice Simmons-Welburn, "From Vision to Reality: Change at the University of Iowa," in Rethinking Reference in Academic Libraries, ed. Anne G. Lipow (Berkeley, Calif.: Library Solutions Pr., 1993), 61.

29. Two thoughtful explorations of the contemporary service environment are: Herbert $S$. White, "Information Technology, Users, and Intermediaries in the 21st Century: Some Observations and Predictions," in Opportunity 2000: Understanding and Serving Users in an Electronic Library. 15th International Essen Symposium, 12-15 October 1992: Festschrift in Honour of Herbert S. White, eds. A. H. Helal and J. W. Weiss (Essen: Universitaetsbibliothek Essen, 1993), 1-14; Rebecca R. Martin, “The Paradox of Public Service: Where Do We Draw the Line?" College \& Research Libraries 51 (January 1990): 20-26.

30. Lucy Siefert Wegner, "Is It True What They Say?: The Library on a Credit Card," Journal of Academic Librarianship 22 (1996): 51-52. For a dated, but still meaningful, exploration of some of these same issues, see Pat Molholt, "On Converging Paths: The Computing Center and the Library," Journal of Academic Librarianship 11 (March 1985): 284-88.

31. For an articulation and detailed analysis of the salient features of the collection-centered and user-centered library paradigms, see Francis Miksa, "The Future of Reference II: A Paradigm of Academic Library Organization," CERL News 50 (Oct. 1989): 780-90.

32. Carolyn Dusenbury and Barbara G. Pease, "The Future of Instruction," Journal of Library Administration 20, nos. 3-4 (1995): 114.

33. Two exceptional works on the nature and impact of networked computer communication and the emergence of the ethic of collaboration are: Lee Sproull and Sara Kiesler, Connections: New Ways of Working in the Networked Organization (Cambridge, Mass.: MIT Pr., 1991), which stresses communication technology and its immediate consequences on organizations; Michael Schrage, Shared Minds: The New Technologies of Collaboration (New York: Random House, 1990), which focuses on the long-term effects of networked communication on organizations and the ways in which organizations can maximize the benefits of such changes.

34. James M. Rosser and James I. Penrod, "Computing and Libraries: A Partnership Past Due," CAUSE/EFFECT 13, no. 2 (summer 1990): 20-24. For good conceptual frameworks, see Sheila D. Creth, "Creating a Virtual Information Organization: Collaborative Relationships between Libraries and Computing Centers," Journal of Library Administration 19 (1993): 111-32; eds. Anne G. Lipow et al, Building Partnerships: Computing and Library Professionals (Berkeley, Calif.: Library Solutions Pr., 1995). The latter also provides several case studies.

35. See, in particular, Jim Pepin's remarks in Richard Lacy, Chris Ferguson, and Jim Pepin, "Campus Partnering between Library and Computing Services: A Bottom-Up Evolutionary Model for Integrating Services," EDUCOM '95, Nov. 1995, Portland, Ore., transcribed at http://wwwlib.usc.edu/Info/Leavey/campus_partnering.html, (June 1996).

36. Pescovitz, "Reality Check"; Cynthia N. James-Catalano, "Look to the Librarians," Internet World 7, no. 8 (Aug. 1996): 28-30; Bonnie A. Mardi et al, "Put a Good Librarian, Not Software, in the Driver's Seat," Christian Science Monitoy (June 4, 1996), 18.

37. Mardi et al, "Put a Good Librarian," 18. 